\title{
P1189 - Family history of diabetes and differences in awareness about 'Diet and Diabetes' among young people in Karachi , Pakistan
}

\section{DIABETES EDUCATION -}

Author: Soha Alam Rehmani.

Institution : DOW UNIVERSITY OF HEALTH SCIENCES

Country: Karachi, Pakistan.

\section{Background}

Diabetes rates are expected to increase in Pakistan and today's youth need to take actions now to prevent their future risk of developing diabetes. Understanding level of awareness and subgroup differences is essential to develop effective awareness programs. Understanding Family history of diabetes related differences would be helpful in making diabetes prevention education for youth more effective

\section{$\operatorname{Aim}$}

The purpose of this study is to find out Family history of diabetes differences in awareness about "Diet and Diabetes" among young people in Karachi Pakistan.

\section{Method}

This study was conducted by Nutrition foundation of Pakistan's

"Public Health Educators" group. Data was collected through an online structured questionnaire disseminated through survey monkey through NFP and other sources. The Questionnaire had a total of ten

questions about knowledge. T-test Chi square test was applied to estimate statistical significance of differences in nutrition knowledge.

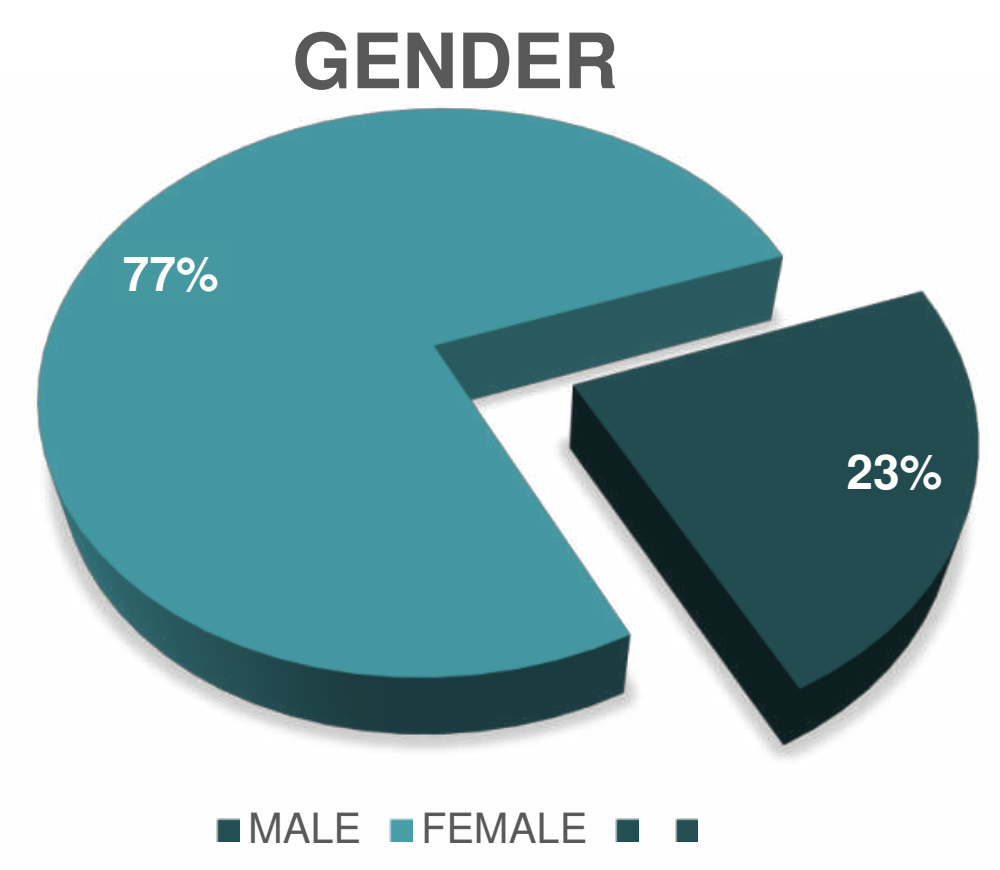

\section{Result}

Data was collected from 100 respondents till 21.4.2017 and will continue for next 2 weeks. Majority of the subjects (55\%) were aged 18-20,34\% were 21-25 years old and remaining 15-18 years old, Though differences in total knowledge score were not significantly different in individual question significant differences were noted. For example a significantly higher proportion of girls $(64 \%)$ knew that "for people with diabetes, besides sugars, it is important to limit their intake of salt" as compared to boys (34\%) $\mathrm{P}=0.007$.

\section{Discussions}

This study evidenced that there may be significant difference in knowledge of male and female youth and larger studies should be done to explore such difference and actions should be taken to improve young people's diabetes related knowledge.

\begin{tabular}{ccccc} 
& Knowledge & \multicolumn{2}{c}{ Gender } & Total \\
& & Male & Female & \\
\multirow{3}{*}{ Poor } & Count & 3 & 17 & 20 \\
& $\%$ & $12.5 \%$ & $22.7 \%$ & $20.2 \%$ \\
\multirow{3}{*}{ Good } & Count & 21 & 58 & 79 \\
& $\%$ & $87.5 \%$ & $77.3 \%$ & $79.8 \%$ \\
\multirow{3}{*}{ Total } & Count & 24 & 75 & 99 \\
& $\%$ & $100.0 \%$ & $100.0 \%$ & $100.0 \%$
\end{tabular}

\begin{tabular}{|c|c|c|c|}
\hline \multicolumn{4}{|c|}{ Gender } \\
\hline \multicolumn{2}{|c|}{ Male } & \multicolumn{2}{|c|}{ Female } \\
\hline & Mean & & Mean \\
\hline Overall & 5.75 & Overall & 6.18 \\
\hline 17 to 20 years & 5.72 & 17 to 20 years & 5.76 \\
\hline 21 to 23 years & 5.98 & 21 to 23 years & 6.75 \\
\hline
\end{tabular}

